\title{
The influence of thermal after-treatment on the adhesion of 3D prints on textile fabrics
}

\author{
Daniel Görmer, Jannik Störmer, Andrea Ehrmann* \\ Bielefeld University of Applied Sciences, Faculty of Engineering and Mathematics, Bielefeld, Germany \\ ${ }^{*}$ Corresponding author E-mail address: andrea.ehrmann@fh-bielefeld.de
}

\section{INFO}

CDAPT, ISSN 2701-939X

Peer reviewed article

2020, Vol. 1, No. 2, pp. 104-110

DOI 10.25367/cdatp.2020.1.p104-110

Received: 16 August 2020

Accepted: 06 September 2020

Available online: 22 November 2020

\begin{abstract}
$3 D$ printing belongs to the emerging technologies of our time. While it enables producing new structures and makes individualized products affordable, 3D printed objects still suffer from low production speed and often insufficient mechanical properties. Both these problems can be tackled by combining 3D printing with substrates prepared by conventional technologies, e.g. textile fabrics. In this case, the adhesion between both partners is most challenging and defines for which possible applications such composites are suitable. Here, we report on a new approach to increase the adhesion between $3 D$ printed materials and warp knitted fabrics, showing that in some cases a thermal after-treatment, in the simplest case performed by ironing, is able to significantly increase the adhesion between both materials.
\end{abstract}

\section{Keywords}

3D printing,

warp knitted fabrics,

ironing,

thermal after-treatment,

adhesion,

nozzle-textile distance

(c) 2020 The authors. Published by CDAPT.

This is an open access article under the CC BY-NC-ND license https://creativecommons.org/licenses/ peer-review under responsibility of the scientific committee of the CDAPT.

\section{Introduction}

While 3D printing was originally mostly used for rapid prototyping, nowadays these techniques are more and more often used for preparing real objects with real applications. While some of these applications, such as 3D printing of microfluidics of microelectromechanical systems (MEMS), mostly strive for high resolution and accuracy [1], other applications necessitate especially good mechanical properties [2-4].

One of the possibilities to increase the tensile properties and at the same time reduce production time is 3D printing on textile fabrics, in this way adding a desired stiffness to certain areas of textiles due to functional or design purposes [5], while the main fabric is produced in a conventional way. Such composites, however, often suffer from lacking adhesion between both partners. 
This is why several research groups investigated the adhesion between 3D printed parts and textile fabrics. In most cases, 3D printing was performed using the fused deposition modeling (FDM) process, while most recently the first proof-of-principle showed that stereolithography (SLA) can also be applied to print 3D objects on many textile fabrics [6]. Here, however, we concentrate on the common FDM technology.

In recent studies, several material and printing parameters were found to influence the adhesion of 3D printed layers on textile fabrics. Eutionnat-Diffo et al. reported the printing bed temperature as well as woven fabric parameters to have an impact on the adhesion [7]. Generally, the structure of the textile fabric, especially pores and hairs as possibilities for the 3D printing polymer to penetrate into the fabric or to build other form-locking connections, is an important parameter [8-11]. One of the most important parameters is the distance between nozzle and fabric surface, defining with how much force the molten polymer is pressed into the fabric pores [12,13]. For a broader overview of the influence of diverse parameters on the textile-polymer adhesion, the reader is referred to References 14 and 15.

Besides these parameters, chemical and physical surface treatments of the textile fabric before printing and the composite afterwards were investigated. According to the Korger law [16], in most cases hydrophilic surfaces support 3D printing on them, while hydrophobic ones often result in lower adhesion [17]. On the other hand, thermal after-treatments were examined, printing with poly(lactic acid) (PLA) on jeans-like cotton woven fabrics [17]. In this previous study, ironing slightly decreased the adhesion force, without showing a significant difference.

Here, we report on 3D printing especially on warp knitted fabrics with four different polymers. While some of the aforementioned relations are underlined by the recent study, ironing as a simple way of thermal after-treatment unexpectedly showed a large impact in some cases, opposite to our previous study.

\section{Materials and Methods}

3D printing was performed using the FDM printer CR-10S Pro (Creality, Shenzhen, China) with nozzle diameter $0.4 \mathrm{~mm}$. In all experiments, rectangles of $120 \mathrm{~mm} \times 25 \mathrm{~mm} \times 0.8 \mathrm{~mm}$ were printed, using a layer height of $0.2 \mathrm{~mm}$ and $100 \%$ infill with $\pm 45^{\circ}$ orientation.

For the tests, four different filaments were printed (nozzle and printing bed temperatures in brackets): PLA (white, from Creality, $200{ }^{\circ} \mathrm{C} / 45{ }^{\circ} \mathrm{C}$ ); co-polyester (CPE) (black, from Filamentworld, $260{ }^{\circ} \mathrm{C} /$ $85^{\circ} \mathrm{C}$ ); polyethylene terephthalate glycol (PETG) (green, from Filamentworld, $215{ }^{\circ} \mathrm{C} / 70{ }^{\circ} \mathrm{C}$ ); and thermoplastic polyurethane (TPU) (orange, from Recreus, $230^{\circ} \mathrm{C} / 30^{\circ} \mathrm{C}$ ). In addition to the "raw" printed samples, further samples were ironed after 3D printing, using an electric iron Quigg DB 2016.19/5218 (Globaltronics $\mathrm{GmbH} \&$ Co. KG, Hamburg, Germany), at grade 10 (“jeans”), equivalent to the common setting ${ }^{* * *}$ and defining a temperature of $(185 \pm 15){ }^{\circ} \mathrm{C}$, according to the producer. Ironing was performed with a rotating movement from the back of the sample, i.e. on the textile side, for $15 \mathrm{~s}$, letting the sample cooling down for 2 min and afterwards again ironing for $15 \mathrm{~s}$, to avoid overheating and at the same time to average over a relatively long duration due to the well-known temperature variation of bimetal irons. The iron was not pressed down during ironing; its mass without the power cable is approx. $1240 \mathrm{~g}$.

The warp knitted fabrics on which printing was performed were prepared on different machines (all by Karl Mayer, Obertshausen, Germany), using different warp knitted structures and yarns. Table 1 depicts scans of the four samples with corresponding machines, machine gauges and yarn materials.

Examinations were performed by a Sauter universal testing machine at a speed of $100 \mathrm{~mm} / \mathrm{min}$. Tests were performed according to DIN 53530 and evaluated according to ISO 6133, using the method for more than 20 peaks. This means that one end of the fabric was manually separated from the fabric so that these separated ends could be clamped in the testing machine, allowing for measuring the forcedisplacement curves. The test process is sketched in Fig. 1. 
Table 1. Warp knitted fabrics used for printing.

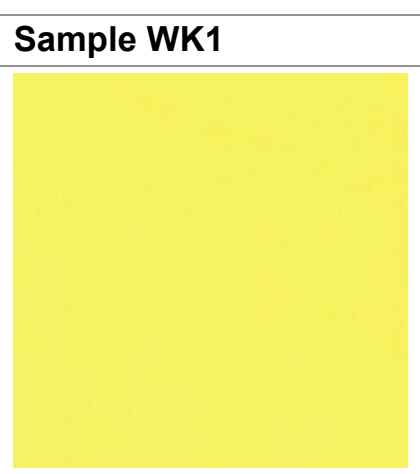

HKS 2-3 E, E40

Elastane / polyamide 6

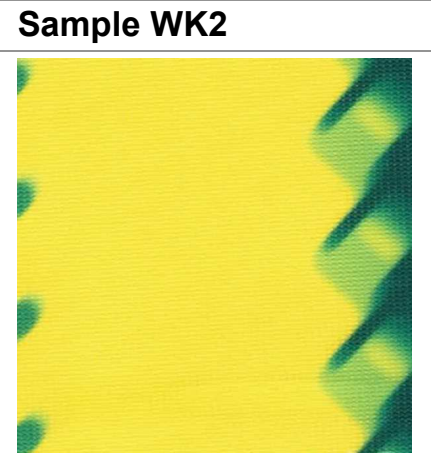

HKS 3-M, E28

Polyester, flat, dull

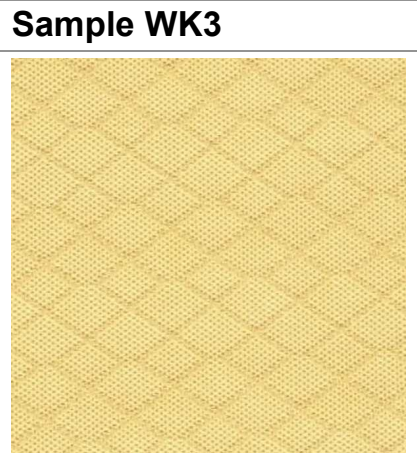

RSE 5 EL, E28

Elastane / polyamide 6
Sample WK4

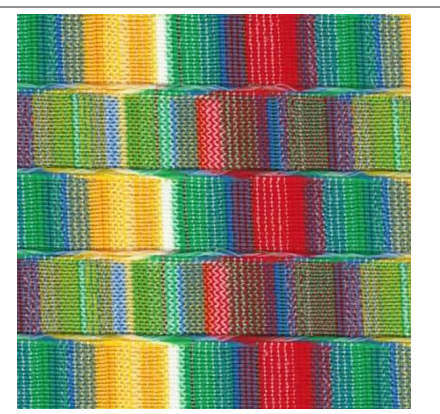

HKS 4-M EL, E28

Polyester, semi-dull

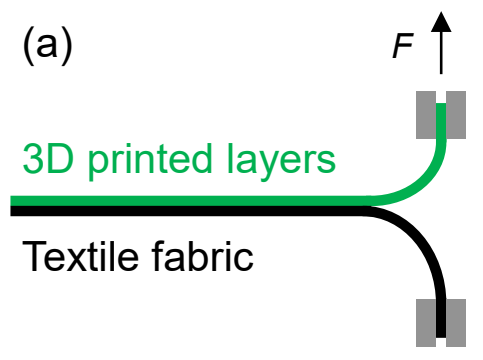

(b)

$F \uparrow$

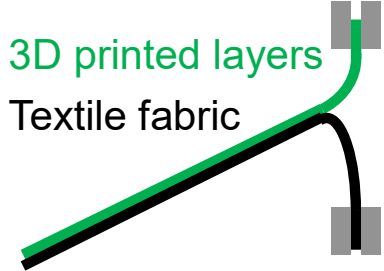

Fig. 1 (a) Test process according to DIN 53530. (b) For the rigid filaments, the 3D printed layers are more linearly shaped than the textile fabric.

Photographs of the samples were taken by a Nikon D750 with an objective Sigma $105 \mathrm{~mm}$ 1:2.8 DG Macro HSM.

\section{Results and Discussion}

The results of the first test series, testing combinations of all four polymers with the four warp knitted fabrics, are depicted in Fig. 2.

Comparing these graphs, it is obvious that the adhesion on the samples WK 1 and WK 3 is smaller than on samples WK2 and WK4. Both samples WK1 and WK3 are prepared from elastane and polyamide 6 yarns, correspondingly these two samples are elastic, while the others have a very low elasticity. Possible explanations for this finding are, on the one hand, the sample structure - samples WK2 and WK4 have larger pores and thus allow the molten polymer to penetrate deeper into the fabric. On the other hand, the elasticity of WK1 and WK3 make it harder to press the polymers into the fabrics since they are fixed only along the sample borders and thus can be moved by the moving nozzle. Finally, samples WK2 and WK4 are highly hydrophilic, with water drop penetration times below $1 \mathrm{~s}$, while the drop penetration time on samples WK1 and WK3 is in the order of 2-3 s. Apparently here different reasons can be found why a higher adhesion can be reached on samples WK2 and WK4.

Next, the different polymers can be compared. Here it can be recognized that TPU and CPE give the best results, while PETG and PLA show in most cases much lower adhesion. While it is known from the literature that elastic filaments, such as TPU, usually show a high adhesion [18], no reports can be found about 3D printing CPE on textile fabrics. Our first test of this polymer suggests that CPE may have a high potential for direct printing on textile fabrics, e.g. for applications in orthoses where a very high adhesion is necessary [19]. This is especially important since PLA is often regarded as the rigid polymer with the highest adhesion, compared with nylon (polyamide), acrylonitrile butadiene styrene (ABS) and other polymers [12], and here it is outperformed by CPE in most cases. 

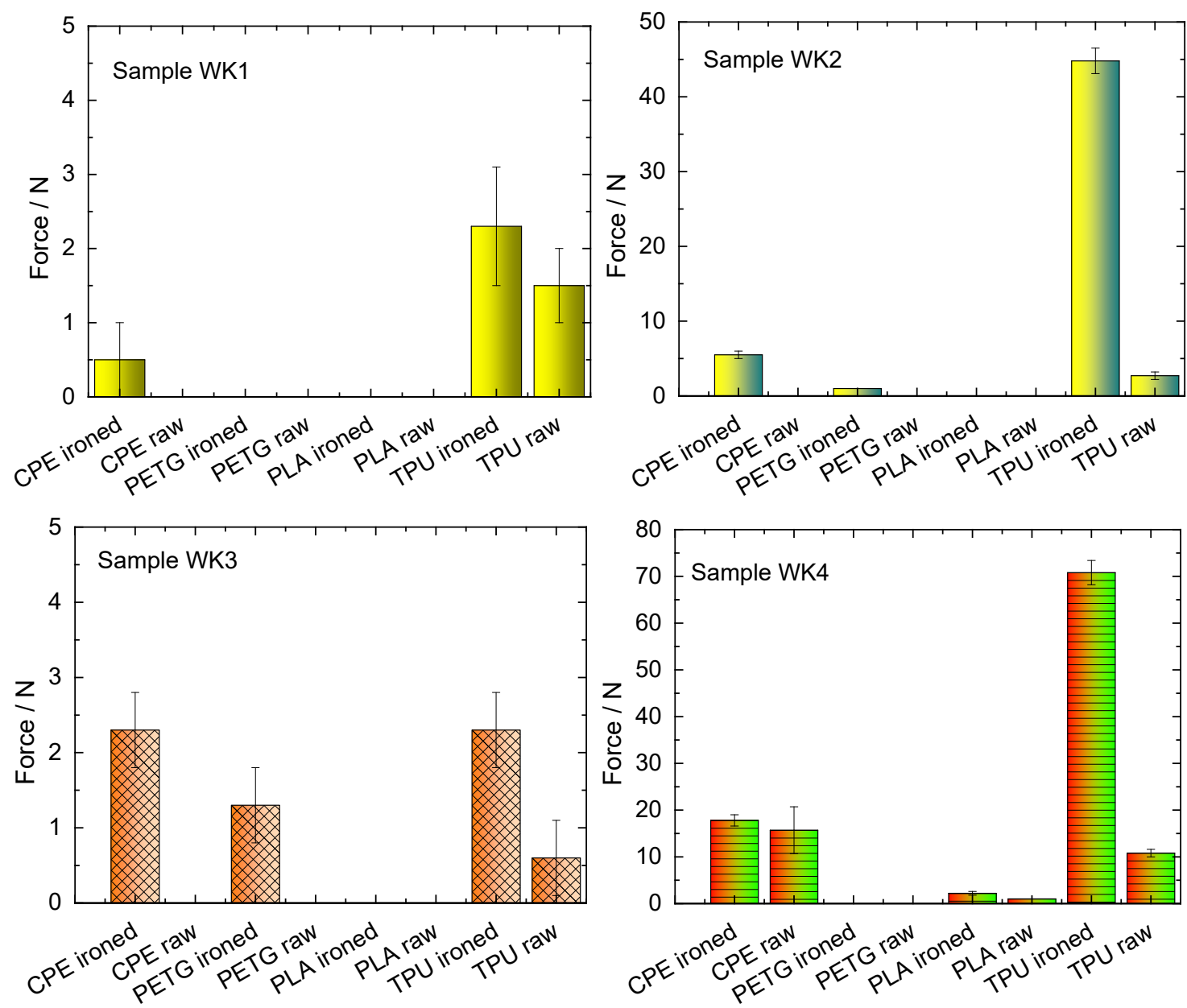

Fig. 2 Adhesion forces, measured for the four textile fabrics under investigation, measured in combination with different $3 D$ printing polymers.

Besides, the influence of ironing shall be examined. While our former study showed a small reduction of the adhesion due to ironing, this finding is different here. For CPE, ironing is supportive on samples WK1-3 and not disadvantageous on samples WK4. PETG in most cases fall apart from the textile substrates before testing; only after ironing, it shows a very low adhesion on samples WK2 and WK3. For PLA, ironing does not seem to make a difference, which is similar to the finding of the previous study. Finally, for TPU, only on the finest sample WK1 ironing does not make a significant difference, while on the other substrates, ironing increases the adhesion approximately by a factor of 4-17.

Apparently, the influence of ironing is worth a deeper investigation. This is especially valid since in the tests depicted in Fig. 2, the distance between nozzle and printing bed was optimized manually for each sample without performing a full test series. This means that the impact of ironing on the adhesion may also depend on this distance - it can be imagined that ironing is especially supportive if the nozzle-textile distance was too large during printing so that the filament has not yet been pressed into the fabric with enough pressure, which could be finalized by ironing.

This is why the next test series concentrated on sample WK4 which showed a strong impact of ironing TPU printed samples, comparing the impact of ironing for different distances between nozzle and printing bed. Fig. 3 depicts the results of the corresponding adhesion tests. A distance of $0.2 \mathrm{~mm}$ is automatically set by the printer for a first-layer thickness of $0.2 \mathrm{~mm}$. Printing slightly below this value would be typical for printing on the pure glass bed. Here, however, a textile fabric of thickness $0.62 \mathrm{~mm}$ is placed on the printing bed, meaning that a distance of approx. $0.8 \mathrm{~mm}$ would be comparable to the usual distance for printing on the glass bed. As already pointed out in former publications [12], printing "below" the surface of the textile fabric is necessary to optimize the adhesion. 


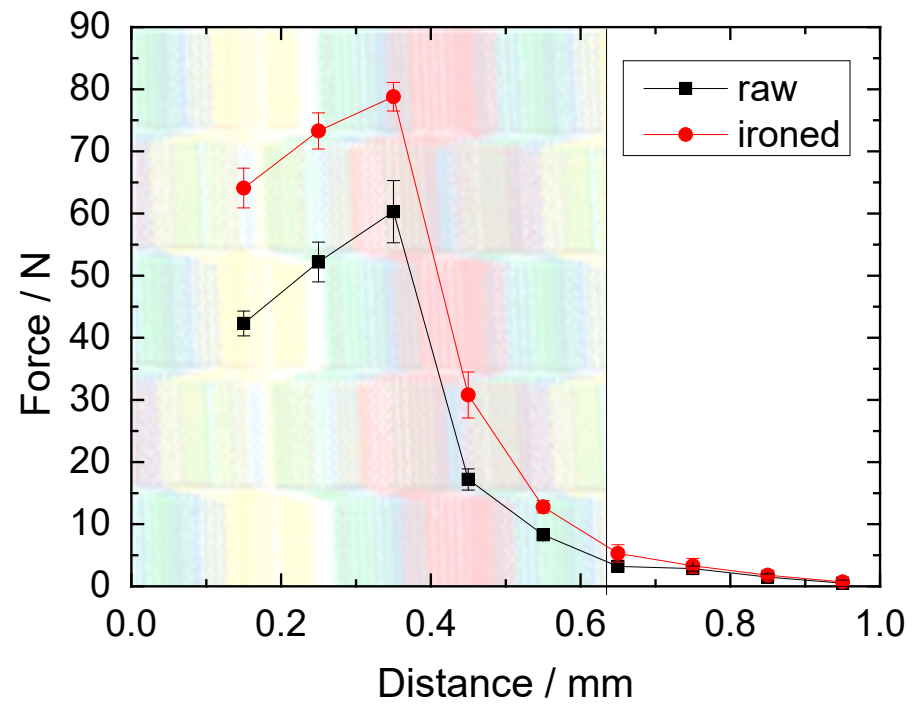

Fig. 3 Adhesion forces, measured for sample WK4, in dependence of the distance between nozzle and printing bed for raw and ironed samples.

As Fig. 3 clearly shows, ironing cannot be used as a substitute for this first creation of a form-locking connection. Instead, this thermal after-treatment always increases the adhesion force, independent from the original printing distance. This means that, at least in this combination of TPU with relatively dense, inelastic polyester warp knitted fabric, the adhesion between both materials should be optimized by controlling the distance between nozzle and printing bed as well as by an additional thermal aftertreatment.

To investigate the reasons for this effect more in detail, Fig. 4 depicts the back of different samples after the adhesion tests.
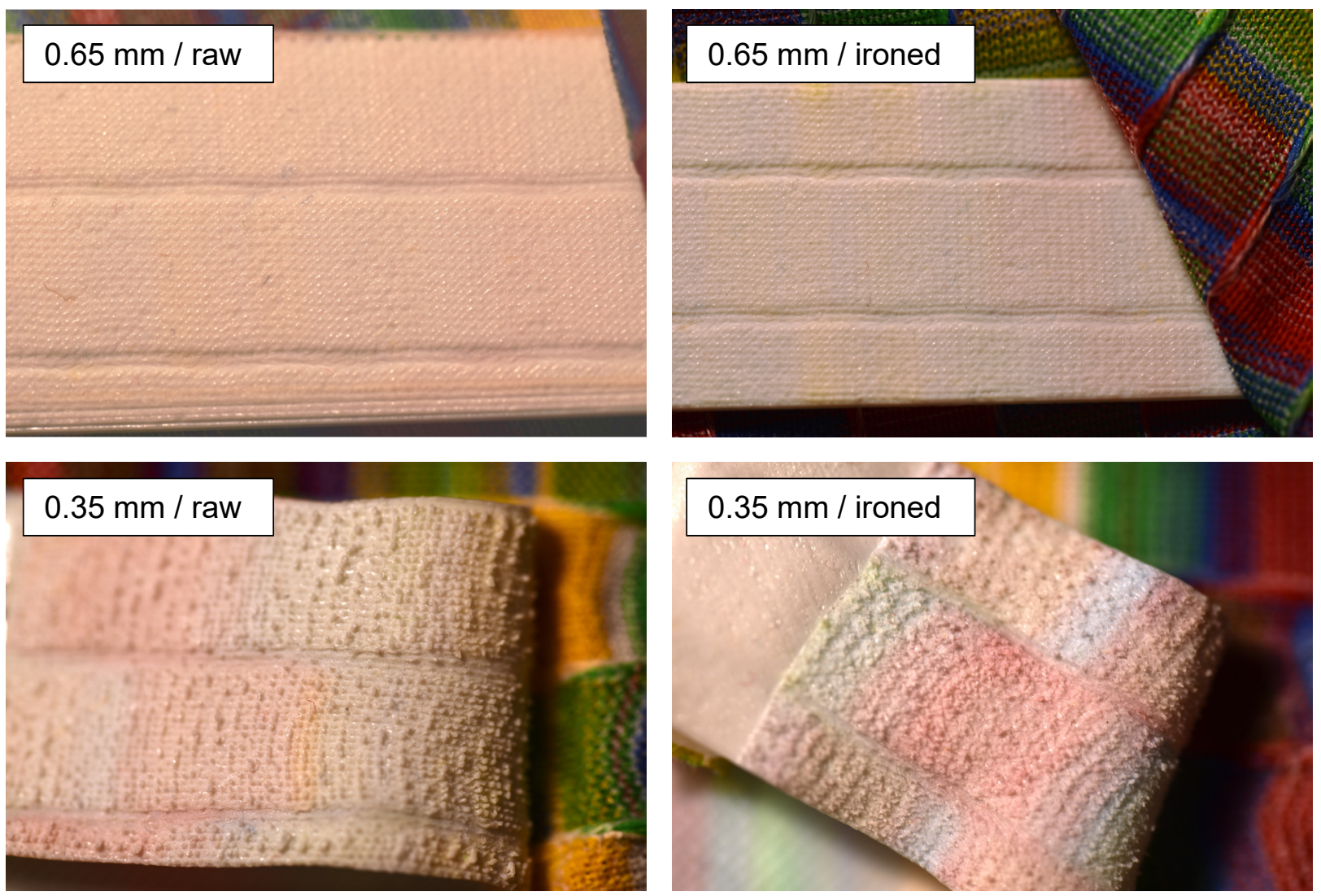

Fig. 4 Back of different samples (cf. insets) after the adhesion test. 
On the one hand, comparison between the samples printed at distances of $0.35 \mathrm{~mm}$ (optimum distance, cf. Fig. 3) and $0.65 \mathrm{~mm}$ (slightly "outside" the fabric) clearly shows that only a slight imprint of the textile surface is visible on the latter, while at the optimum distance, the polymer was pressed into the fabric, after the adhesion test clearly showing small spikes which were pulled out of the pores of the fabric. This finding is identical to previous experiments where different z-distances were compared by crosssectional images [12].

On the other hand, due to the colored warp knitted fabric, it is also possible to investigate the color transferred to the white polymer. Comparing both samples printed at the larger distance of $0.65 \mathrm{~mm}$, no significant differences are visible, while the ironed sample may show slightly more colors. For the samples printed at the optimum distance of $0.35 \mathrm{~mm}$, however, the ironed one is clearly more colored.

We can thus assume that the relatively high ironing temperature - near to the melting temperature of polyester of typically $230-260{ }^{\circ} \mathrm{C}$ - was sufficient to start softening and slightly melting the textile material. In this way, a chemical bonding may have been formed during ironing, while the previous pressure during printing, applied by an optimized z-distance, results in a form-locking (physical) bonding. Apparently, here two different mechanisms interact, both able to increase the adhesion between polymer and textile fabric independently.

Comparing the values in Fig. 3 with those depicted in Fig. 2 for TPU printed on sample WK4 again underlines the importance of optimizing the distance. While for precisely controlled distances, the forces between raw and ironed composites (Fig. 3) differ maximally by approx. a factor of 1.5 , this difference is much higher for the comparison given in Fig. 2, clearly showing that it is not possible to control the distance well enough manually. This finding can be explained from Fig. 3, showing that a small distance reduction from $0.45 \mathrm{~mm}$ to $0.35 \mathrm{~mm}$ approximately triples the adhesion force.

Generally, as this study shows, printing on textile fabrics in the optimum distance cannot be optically supervised as easily, as it is possible for an experienced user for printing on the common printing bed. Since each textile fabric behaves differently, has different mechanical properties, hairiness, surface structure etc., it is strongly recommended for researchers working in this field to optimize and control the distance carefully, to avoid conclusions of parameter modifications which may be at least partly based on erroneous distance variations.

\section{Conclusions}

3D printing with four different polymers was performed on four warp-knitted fabrics. We report on the first experiment to perform $3 \mathrm{D}$ printing with CPE on textile fabrics, showing that this polymer may be advantageous in comparison to PLA which is most often used in such studies. In addition, opposite to a previous study, a significant influence of a thermal after-treatment, performed by ironing, on the adhesion was found in most cases. Finally, the strong impact of the distance between nozzle and textile surface, revealed in previous studies, was underlined.

Future investigations will concentrate on the impact of ironing on different material combinations to examine whether the correlation found here for TPU and relatively thin fabrics with narrow pores translated to other structures and materials, besides differentiating further between physical and chemical effects.

\section{Acknowledgements}

The authors are grateful for the warp knitted textiles provided by Karl Mayer Textilmaschinen AG, Obertshausen, Germany. 


\section{References}

[1] Blachowicz, T.; Ehrmann, A. 3D printed MEMS technology - recent developments and applications. Micromachines, 2020, 11(4), 434. DOI: 10.3390/mi11040434.

[2] Arunothayan, A. R.; Nematollahi, B.; Ranade, R.; Bong, S. H.; Sanjayan, J. Development of 3D-printable ultrahigh performance fiber-reinforced concrete for digital construction. Construction and Building Materials, 2020, 257, 119546. DOI: 10.1016/j.conbuildmat.2020.119546.

[3] Afshar, A.; Mihut, D. Enhancing durability of 3D printed polymer structures by metallization. J. Mater. Sci. Technol., 2020, 53, 185-191. DOI: 10.1016/j.jmst.2020.01.072.

[4] Oviedo, A. M.; Puente, A.H.; Bernal, C.; Perez, E. Mechanical evaluation of polymeric filaments and their corresponding 3D printed samples. Polym. Test., 2020, 88, 106561. DOI: 10.1016/j.polymertesting.2020.106561.

[5] Spahiu, T.; Fafenrot, S.; Grimmelsmann, N.; Piperi, E.; Shehi, E.; Ehrmann, A. Varying fabric drape by 3Dimprinted patterns for garment design. IOP Conf. Ser.: Mater. Sci. Eng., 2017, 254, 172023. DOI: 10.1088/1757-899X/254/17/172023.

[6] Grothe, T.; Brockhagen, B.; Storck, J. L. Three-dimensional printing resin on different textile substrates using stereolithography: A proof of concept. J. Eng. Fibers Fabr., 2020, 15, 1558925020933440. DOI: 10.1177/1558925020933440.

[7] Eutionnat-Diffo, P. A.; Chen, Y.; Guan, J. P.; Cayla, A.; Campagne, C.; Zeng, X. Y.; Nierstraz, V. Stress, strain and deformation of poly-lactic acid filament deposited onto polyethylene terephthalate woven fabric through 3D printing process. Sci. Rep., 2019, 9, 14333. DOI: 10.1038/s41598-019-50832-7.

[8] Narula, A.; Pastore, C.; Schmelzeisen, D.; El Basri, S.; Schenk, J.; Shajoo, S. Effect of knit and print parameters on peel strength of hybrid 3D printed textiles. J. Text. Fibrous Mater., 2018, 1, 2515221117749251. DOI: 10.1177/2515221117749251.

[9] Meyer, P.; Döpke, C.; Ehrmann, A. Improving adhesion of three-dimensional printed objects on textile fabrics by polymer coating. J. Eng. Fibers Fabr., 2019, 14, 1558925019895257. DOI: 10.1177/1558925019895257.

[10] Calvo, J. O.; Martin, A. C.; Ferradas, M. I. R.; Morcillo, P. L. F.; Munoz, L. M.; Camo, P. M. Additive manufacturing on textiles with low-cost extrusion devices: Adhesion and deformation properties. Dyna, 2019, 64, 8893. DOI: $10.6036 / 8893$.

[11] Mpofu, N. S.; Mwasiagi, J. I.; Nkiwane, L. C.; Njuguna, D. Use of regression to study the effect of fabric parameters on the adhesion of 3D printed PLA polymer onto woven fabrics. Fashion and Textiles, 2019, 6, 24. DOI: 10.1186/s40691-019-0180-6.

[12] Grimmelsmann, N.; Kreuziger, M.; Korger, M.; Meissner, H.; Ehrmann, A. Adhesion of 3D printed material on textile substrates. Rapid Prototyp. J., 2018, 24(1), 166-170. DOI: 10.1108/RPJ-05-2016-0086.

[13] Spahiu, T.; Al-Arabiyat, M.; Martens, Y.; Ehrmann, A.; Piperi, E.; Shehi, E. Adhesion of 3D printing polymers on textile fabrics for garment production. IOP Conf. Ser.: Mater. Sci. Eng., 2018, 459, 012065. DOI: 10.1088/1757-899X/459/1/012065.

[14] Sitotaw, D. B.; Ahrendt, D.; Kyosev, Y.; Kabish, A. K. Additive manufacturing and textiles - state of the art. Appl. Sci., 2020, 10, 5033. DOI: 10.3390/app10155033.

[15] Kozior, T.; Blachowicz, T.; Ehrmann, A. Adhesion of three-dimensional printing on textile fabrics: Inspiration from and for other research areas. J. Eng. Fibers Fabr., 2020, 15, 1558925020910875. DOI: $10.1177 / 1558925020910875$.

[16] Korger, M.; Bergschneider, J.; Lutz, M.; Mahltig, B.; Finsterbusch, K.; Rabe, M. Possible Applications of 3D Printing Technology on Textile Substrates. IOP Conf. Ser.: Mater. Sci. Eng., 2016, 141, 012011. DOI: 10.1088/1757-899X/141/1/012011.

[17] Kozior, T.; Döpke, C.; Grimmelsmann, N.; Juhász Junger, I.; Ehrmann, A. Influence of fabric pretreatment on adhesion of three-dimensional printed material on textile substrates. Adv. Mech. Eng., 2018, 10, 792316. DOI: $10.1177 / 1687814018792316$.

[18] Korger, M.; Glogowsky, A.; Sanduloff, S.; Steinem, C.; Huysman, S.; Horn, B.; Ernst, M.; Rabe, M. Testing thermoplastic elastomers selected as flexible three-dimensional printing materials for functional garment and technical textile applications. J. Eng. Fibers Fabr., 2020, 15, 1558925020924599. DOI: $10.1177 / 1558925020924599$.

[19] Ahrendt, D.; Karam, A. R. Development of a computer-aided engineering-supported process for the manufacturing of customized orthopaedic devices by three-dimensional printing onto textile surfaces. J. Eng. Fibers Fabr., 2020, 15, 1558925020917627. DOI: 10.1177/1558925020917627. 